\title{
Natural bioadhesive biodegradable nanoparticles-based topical ophthalmic formulations for sustained celecoxib release: In vitro Study
}

\author{
Mohammed Mostafa Ibrahim ${ }^{1,2}$, Abd-Elgawad Helmy Abd-Elgawad ${ }^{2}$, Osama Abd-Elazeem Soliman² and Monica M. Jablonski ${ }^{*}$ \\ *Correspondence: mjablonski@uthsc.edu \\ 'Department of Ophthalmology, Hamilton Eye Institute, University of Tennessee Health Science Center, Memphis, TN, USA. \\ ${ }^{2}$ Department of Pharmaceutics, Faculty of Pharmacy, Mansoura University, Mansoura 35516, Egypt.
}

\begin{abstract}
Background: Our goal was to prepare and evaluate topical ophthalmic formulations containing optimized celecoxib-loaded bioadhesive cationic chitosan or anionic alginate nanoparticles for sustained release of celecoxib.

Methods: Nanoparticles were prepared using a spontaneous emulsification solvent diffusion method. Different concentrations of polymers, emulsifier and stabilizers were used to optimize our formulations. The formulation that gave the lowest particle size and polydispersity index and the highest zeta potential was selected and subjected to further studies. The optimized celecoxibloaded NPs were characterized with regard to their particle size, polydispersity index, zeta potential, morphology and drug content. Celecoxib-loaded NPs were incorporated in topical ophthalmic dosage forms including eye drops, temperature-triggered in situ gelling system and preformed gel. All formulations were then characterized regarding their $\mathrm{pH}$, viscosity, uniformity of drug content, in vitro release study and in vitro cytotoxicity.

Results: Results of the optimization studies of both celecoxib-loaded chitosan and alginate nanoparticles respectively, are: particle size of $113.33 \pm 4.08 \mathrm{~nm}$ and $154.67 \pm 5.06 \mathrm{~nm}$; zeta potential of $+36.92 \pm 3.38 \mathrm{mV}$ and $-36.5 \pm 4.7 \mathrm{mV}$; and encapsulation efficiencies of $89.88 \pm 4.17 \%$ and $75.38 \pm 2.98 \%$. Transmission electron microscopic analysis revealed that all nanoparticles have distinct spherical shapes comprising of a solid dense core covered with evenly distributed coat. oreover, all formulations possessed $\mathrm{pH}$ and viscosity values that are compatible with the eye and have uniform drug contents that complied with the US Pharmacopeial (USP) official requirement. In vitro release data of ophthalmic formulations showed a sustained release without any burst effect and the formulations followed a Higuchi non-Fickian diffusion mechanism. The results of in vitro cell toxicity revealed that all the prepared formulations are non-toxic, as the percentage cell viability ranged from 89.9 to $97.7 \%$.

Conclusions: These formulations provide a great deal of flexibility to the formulation scientist whereby the sizes and zeta potentials of the formulations can be tuned to suit the need using scalable and robust methodologies. This could thus serve as a potential drug delivery system for both the anterior and posterior eye diseases.
\end{abstract}

Keywords: Chitosan, alginate, ophthalmic, celecoxib, nanoparticles, formulations, cytotoxicity

\section{Background}

One of the most attractive aspects of drug delivery research is the ability to design nanocarriers that are able to deliver drugs to the right place, at the appropriate times and at accurate concentrations. These nanocarriers are nanoparticulate systems that entrap drugs and may prevent or minimize drug degradation and metabolism, which possibly increases cellular uptake [1]. Nanoparticulates have many advantages such as a long shelf life, being made from safe materials-including synthetic and natural biodegradable polymers, lipids and polysaccharides-and having the ability to pass important mucosal barriers, such as the intestinal, nasal and ocular barriers [2].

A major drawback of conventional topical ophthalmic drug delivery systems is the rapid and extensive loss of drug caused by the drainage through the nasolachrymal duct and high tear fluid turnover [3]. Several studies have attempted to increase the corneal penetration of drugs using colloidal drug delivery systems, such as liposomes [4], nanoparticles [5] and nanocapsules [6], which would in turn improve the therapeutic effect. Unfortunately, the short residence time of these colloidal carrier systems on the ocular surface remains a major challenge for the therapy of diseases of the external portions of the eye. Consequently, the design of a mucoadhesive nanocarrier system with improved drug delivery properties toward the ocular surface would be a promising step towards the treatment these diseases. It is predicted that the use of mucoadhesive polymers, which may interact with cornea and conjunctiva, will increase the concentration and residence time of its associated drug. Among the wide variety of natural mucoadhesive polymers reported in the literature, chitosan (CS) and sodium alginate (ALG) are the most widely used, safe, biocompatible and biodegradable ones [7].

$$
\text { Chitosan, [a(1-4)2-amino 2-deoxy } \beta \text {-D glucan] (CS), is }
$$

(C) 2013 Jablonski et al; licensee Herbert Publications Ltd. This is an Open Access article distributed under the terms of Creative Commons Attribution License (http://creativecommons.org/licenses/by/3.0). This permits unrestricted use, distribution, and reproduction in any medium, provided the original work is properly cited. 
a deacetylated form of chitin, a polysaccharide present in abundance in the shells of crustaceans [8]. It has been a polymer of choice because of its unique properties including bioadhesiveness, biodegradability, biocompatibility [9], as well as its penetration enhancing properties in both in vitro and in vivo conditions [10]. Its biodegradability is due to its degradation by lysozyme, an enzyme that is available in serum [11] and is highly concentrated in the lacrimal fluid [12]. Studies have shown that CS also exhibits antibacterial activity [13]. Finally, CS has recently been proposed as a material with a good potential for topical ocular drug delivery due to its ability to prolong the corneal residence time, as CS nanoparticles can remain attached to the cornea and theconjunctiva for $24 \mathrm{~h}$ [14].

Alginates (ALG) are random, linear and anionic polysaccharides consisting of linear monomers, $\mathrm{a}$-L-guluronic acid and $\beta$-D-mannuronic. Alginates have a long history of use in numerous biomedical applications, including drug delivery systems, as they are biodegradable, biocompatible and mucoadhesive polymers [1]. Alginate polymers are also safe and hemocompatible. They do not accumulate in any major organs and show evidence of in vivo degradation [15]. Sodium alginate is used in a variety of oral, topical and ophthalmic pharmaceutical formulations and it has been specifically used for the aqueous microencapsulation of drugs instead of the conventional solvent based systems [16]. Due to its previously mentioned properties, ALG is considered as an excellent polymer for preparation of biodegradable, biocompatible and mucoadhesive nanoparticles for sustained ophthalmic drug delivery [17]

Non-steroidal anti-inflammatory drugs have been used topically to manage some ophthalmic problems such as enhance mydriasis, reduce postoperative inflammation, and prevent and treat cystoid macular edema associated with cataract surgery. In addition, they can be used to decrease pain and photophobia after refractive surgery and to alleviate itching associated with allergic conjunctivitis [18]. Celecoxib exerts its action through a selective inhibition of the cyclooxygenase-2 enzyme [19]. In addition to its anti-inflammatory role, celecoxib decreases the expression of vascular endothelial growth factor, which makes it a plausible therapy for proliferative diabetic retinopathy, neovascular age-related macular degeneration [20] and some ocular tumors such as retinoblastoma [21] and metastatic uveal melanoma [19].

The most common route of administration for celecoxib in treatment of ocular diseases is oral [22]. This route, however, has many drawbacks including that the amount of drug that reaches the site of action is very low, thus requiring a high dose for a long period of time, which may increase the risk of occurrence of side effects [23]. Several trials have attempted to overcome the drawbacks of its systemic use. For example, Amrite et al., prepared celecoxib in the form of periocular injectable microparticles for treatment of diabetes-induced elevation in retinal prostaglandins, vascular endothelial growth factor, and vascular leakage [24]. In another study, Ayalasomayajula and Kompella prepared subconjunctivally administered celecoxib-poly ( $D, L$ - lactide-co-glycolide) (PLGA) microparticles for sustained retinal drug delivery levels for treatment of diabetes-induced oxidative stress in a rat model [25]. Lastly, Cheruvu et al., prepared celecoxib in two injectable forms i.e., celecoxib suspension in $0.5 \%$ carboxymethylcellulose and celecoxib-loaded poly(L-lactide) (PLA) nanoparticles to study the effect of eye pigmentation on the trans-scleral drug delivery to the retina from both rapid release and sustained release formulations [26]. While these studies showed increased delivery of celecoxib to the posterior segment of the eye, they all required invasive delivery methods. In our study, we sought to formulate celecoxib topical ophthalmic formulations to be administered non-invasively for treatment of both anterior and posterior eye diseases.

In the present study, we report a modified spontaneous emulsification/solvent diffusion method to prepare cationic CS and anionic ALG celecoxib-loaded nanoparticles (NPs) for topical ophthalmic use. We then incorporated the drug-loaded nanoparticles in three different ophthalmic dosage forms including eye drops, a temperature triggered in situ gelling system and a preformed gel. The current study was aimed at developing and optimizing sustained release, mucoadhesive and biodegradable nanoparticles formulations of celecoxib for topical ocular delivery.

\section{Methods \\ Materials}

Celecoxib, hydroxypropylmethylcellulose (HPMC), methylcellulose (Methocel, MC), polyvinyl alcohol (PVA, molecular weight 31,000-50,000 Da), Triton X-100, methyl thiazol tetrazolium (MTT), sodium chloride, potassium chloride, sodium phosphate dibasic, potassium dihydrogen phosphate, absolute ethyl alcohol, acetone and dichloromethane (DCM) were purchased from Sigma-Aldrich (St. Louis, MO). Chitosan (molecular weight 100,000 - 300,000 Da) was purchased from Acros Organics (Fair Lawn, NJ). Sodium alginate (medium viscosity) was purchased from MP Biomedicals (Solon, OH). Soyabean L-a-Lecithin ( $98 \%$ phosphotidyl choline) was purchased from Calbiochem (San Diego, CA). Poloxamer 188 (Pluronic F68; PolyethylenePolypropylene Glycol, block copolymer of ethylene oxide and propylene oxide, average molecular weight $8400 \mathrm{Da}$ ) was purchased from Spectrum Chemical Mfg. Corp. (New Brunswick, NJ). Dimethyl sulfoxide (DMSO) was purchased from ThermoScientific Co. (Rockford, IL). Glacial acetic acid was purchased from Fisher Scientific (Fair Lawn, NJ). Eagle's minimal essential cell culture medium (EMEM) was purchased from ATCC Co. (Manassas, VA). All chemicals utilized for preparing buffers are of the analytical grade. All materials were used as received without any further treatment. 
Ibrahim et al. Journal of Pharmaceutical Technology \& Drug Research 2013,

http://www.hoajonline.com/journals/pdf/2050-120X-2-7.pdf

doi: 10.7243/2050-120X-2-7

Table 1. Composition of CS-NPs and their characterization.

\begin{tabular}{|c|c|c|c|c|c|c|c|c|c|c|}
\hline \multirow[b]{2}{*}{$\begin{array}{l}\text { Formulation } \\
\text { No. }\end{array}$} & \multirow[b]{2}{*}{ CS } & \multicolumn{5}{|c|}{ Ingredients (\% w/v) } & \multicolumn{4}{|c|}{ Evaluations (mean \pm SD) } \\
\hline & & Lecithin & $\begin{array}{l}\text { Poloxamer } \\
188\end{array}$ & PVA & Acetone & DC M & $\begin{array}{l}\text { Distilled } \\
\text { water to }\end{array}$ & $\begin{array}{l}\text { Particle size } \\
(\mathbf{n m})\end{array}$ & PDI & $\begin{array}{l}\text { Zeta } \\
\text { potential }(\mathrm{mV})\end{array}$ \\
\hline 1 & 0.1 & 1 & 1 & ---- & 4 & 8 & 100 & $99.70 \pm 3.99$ & $0.350 \pm 0.051$ & $13.73 \pm 1.451$ \\
\hline 2 & 0.2 & 1 & 1 & ---- & 4 & 8 & 100 & $106.33 \pm 3.58$ & $0.310 \pm 0.01$ & $24.57 \pm 3.551$ \\
\hline 3 & 0.4 & 1 & 1 & ---- & 4 & 8 & 100 & $371.67 \pm 7.02$ & $0.435 \pm 0.021$ & $41.83 \pm 3.351$ \\
\hline 4 & 0.5 & 1 & 1 & ---- & 4 & 8 & 100 & $713.33 \pm 11.11$ & $0.479 \pm 0.016$ & $46.47 \pm 5.513$ \\
\hline 5 & 0.1 & 1 & ---- & 1 & 4 & 8 & 100 & $119.00 \pm 3.00$ & $0.219 \pm 0.005$ & $11.57 \pm 1.929$ \\
\hline 6 & 0.2 & 1 & ---- & 1 & 4 & 8 & 100 & $122.33 \pm 5.53$ & $0.272 \pm 0.003$ & $22.87 \pm 3.503$ \\
\hline 7 & 0.4 & 1 & ---- & 1 & 4 & 8 & 100 & $361.33 \pm 15.50$ & $0.478 \pm 0.015$ & $40.20 \pm 6.081$ \\
\hline 8 & 0.5 & 1 & ---- & 1 & 4 & 8 & 100 & $450.67 \pm 13.06$ & $0.504 \pm 0.007$ & $41.60 \pm 5.624$ \\
\hline 9 & 0.2 & 1 & 0.2 & ---- & 4 & 8 & 100 & $150.00 \pm 9.00$ & $0.539 \pm 0.01$ & $30.10 \pm 3.608$ \\
\hline 10 & 0.2 & 1 & 0.5 & ---- & 4 & 8 & 100 & $122.67 \pm 5.69$ & $0.431 \pm 0.01$ & $26.43 \pm 3.493$ \\
\hline 11 & 0.2 & 1 & 1.5 & ---- & 4 & 8 & 100 & $102.33 \pm 2.08$ & $0.224 \pm 0.034$ & $18.63 \pm 1.462$ \\
\hline 12 & 0.2 & 1 & ---- & 0.2 & 4 & 8 & 100 & $136.33 \pm 3.58$ & $0.439 \pm 0.002$ & $28.83 \pm 2.252$ \\
\hline 13 & 0.2 & 1 & --- & 0.5 & 4 & 8 & 100 & $125.00 \pm 4.05$ & $0.37 \pm 0.01$ & $25.67 \pm 2.929$ \\
\hline 14 & 0.2 & 1 & --- & 1.5 & 4 & 8 & 100 & $105.33 \pm 4.58$ & $0.209 \pm 0.006$ & $17.37 \pm 1.379$ \\
\hline 15 & 0.2 & 0.0 & 1 & ---- & 4 & 8 & 100 & Formation of vis & cous gel and no & JPs were formed \\
\hline 16 & 0.2 & 0.2 & 1 & ---- & 4 & 8 & 100 & $182.22 \pm 7.17$ & $0.144 \pm 0.011$ & $32.51 \pm 5.253$ \\
\hline 17 & 0.2 & 0.5 & 1 & ---- & 4 & 8 & 100 & $145.86 \pm 5.58$ & $0.242 \pm 0.002$ & $29.23 \pm 4.675$ \\
\hline 18 & 0.2 & 1.5 & 1 & ---- & 4 & 8 & 100 & $147.12 \pm 6.31$ & $0.255 \pm 0.01$ & $19.77 \pm 2.580$ \\
\hline 19 & 0.2 & 2 & 1 & ---- & 4 & 8 & 100 & $174.11 \pm 9.57$ & $0.311 \pm 0.031$ & $15.34 \pm 1.876$ \\
\hline $20^{*}$ & 0.3 & 1 & 0.5 & --- & 4 & 8 & 100 & $107.33 \pm 5.53$ & $0.211 \pm 0.008$ & $35.30 \pm 4.20$ \\
\hline 21 & 0.3 & 1 & ---- & 0.5 & 4 & 8 & 100 & $207.00 \pm 10.00$ & $0.361 \pm 0.005$ & $32.22 \pm 3.08$ \\
\hline
\end{tabular}

*The optimized formulation is indicated by the *

\section{Preparation of plain and celecoxib-loaded nanoparticles}

To ensure sterility of our formulations, all tools used for preparation were sterile and all procedures were done under aseptic conditions to avoid any contamination. Also all the final formulations contained $0.01 \% \mathrm{w} / \mathrm{v}$ benzalkonium chloride as an anti-microbial agent. To maintain formulation isotonicity, all ophthalmic dosage forms including eye drops, in situ gelling systems and preformed gels were prepared using isotonic PBS as a vehicle.

Plain NPs were prepared using a spontaneous emulsification solvent diffusion technique $[27,28]$ with some modifications as described in our published method [29]. Tables 1 and $\mathbf{2}$ list the formulation ingredients used in the preparation of NPs in our optimization studies. Briefly, CS or ALG, at concentrations ranging from 0.1 to $0.5 \% \mathrm{w} / \mathrm{v}$, was dissolved in the aqueous phase using a magnetic stirrer at $600 \mathrm{rpm}$. CS was dissolved in a minimal amount of $1 \%$ acetic acid solution and brought to volume with deionized water (DIW), while ALG was dissolved in DIW alone. Poloxamer 188 or PVA, both NP stabilizers, was dissolved in the polymer solution at a concentration ranging from 0.2 to $1.5 \% \mathrm{w} / \mathrm{v}$. The $\mathrm{pH}$ of the CS solutions was adjusted to 4.5 using $0.1 \mathrm{~N} \mathrm{NaOH}$. Lecithin was dissolved in dichloromethane
(DCM) at a concentration ranging from 0.0 to $2 \% \mathrm{w} / \mathrm{v}$, prior to adding acetone to the lecithin organic solution. The organic solution was injected into the aqueous solution (with magnetic stirring, $900 \mathrm{rpm}$ ) at an injection flow rate of $0.8 \mathrm{ml} / \mathrm{min}$ using an infusion pump (Fisher Scientific, Fair lawn, NJ). The emulsion was sonicated (Misonix S-4000, Qsonica LLC, Newtown, CT) at 100\% amplitude for $10 \mathrm{~min}$ in an ice bath followed by stirring overnight at $200 \mathrm{rpm}$ to allow complete evaporation of DCM. The NP dispersion was then filtered through a $1 \mu \mathrm{m}$ Puradisc syringe filter (GE Healthcare, Buckinghamshire, UK) to remove any NP agglomerates. Fifty milliliters of DIW was added to the filtrate to facilitate diffusion of acetone to the aqueous phase. The NP suspension was centrifuged for $2 \mathrm{~h}$ at 60,000 rpm (SORVALL, WX Ultra Series Centrifuge, USA) and the NP pellet was washed three times by resuspension in $20 \mathrm{ml}$ of DIW and recentrifugation to remove excess emulsifiers and trace acetone. The final NP pellet was suspended in $10 \mathrm{ml}$ DIW containing $0.5 \mathrm{gm}$ of trehalose (i.e., $5 \% \mathrm{w} / \mathrm{v}$ ) as a cryoprotectant. After maintenance overnight in at $-80^{\circ} \mathrm{C}$, NPs were lyophilized (Freezone Lyophilizer, Labconco Corporation, USA) for 2 days at $-50^{\circ} \mathrm{C}$ and reduced pressure $(0.002 \mathrm{mbar})$. The freeze-dried NPs were sealed and maintained at $4^{\circ} \mathrm{C}$ until subjected for further 
Table 2. Composition of ALG-NPs and their characterization.

\begin{tabular}{|c|c|c|c|c|c|c|c|c|c|c|}
\hline \multirow[b]{2}{*}{$\begin{array}{l}\text { Formulation } \\
\text { No. }\end{array}$} & \multirow[b]{2}{*}{ ALG } & \multirow[b]{2}{*}{ Lecithin } & \multicolumn{4}{|c|}{ Ingredients (\% w/v) } & \multirow[b]{2}{*}{$\begin{array}{l}\text { Distilled } \\
\text { water to }\end{array}$} & \multicolumn{3}{|c|}{ Evaluations $($ mean $\pm S D)$} \\
\hline & & & $\begin{array}{l}\text { Poloxamer } \\
188\end{array}$ & PVA & Acetone & DCM & & $\begin{array}{l}\text { Particle size } \\
(\mathbf{n m})\end{array}$ & PDI & $\begin{array}{l}\text { Zeta potentia } \\
(\mathrm{mV})\end{array}$ \\
\hline 1 & 0.1 & 1 & 1 & ---- & 4 & 8 & 100 & $101.67 \pm 2.89$ & $0.353 \pm 0.037$ & $-22.00 \pm 2.92$ \\
\hline 2 & 0.2 & 1 & 1 & ---- & 4 & 8 & 100 & $105.00 \pm 4.00$ & $0.295 \pm 0.02$ & $-29.20 \pm 3.31$ \\
\hline 3 & 0.4 & 1 & 1 & ---- & 4 & 8 & 100 & $133.00 \pm 2.36$ & $0.483 \pm 0.027$ & $-44.43 \pm 4.21$ \\
\hline 4 & 0.5 & 1 & 1 & --- & 4 & 8 & 100 & $150.00 \pm 2.65$ & $0.473 \pm 0.01$ & $-47.90 \pm 5.31$ \\
\hline 5 & 0.1 & 1 & ---- & 1 & 4 & 8 & 100 & $117.67 \pm 2.58$ & $0.194 \pm 0.006$ & $-8.90 \pm 1.75$ \\
\hline 6 & 0.2 & 1 & ---- & 1 & 4 & 8 & 100 & $126.56 \pm 3.11$ & $0.261 \pm 0.051$ & $-15.63 \pm 1.47$ \\
\hline 7 & 0.4 & 1 & ---- & 1 & 4 & 8 & 100 & $144.33 \pm 2.08$ & $0.243 \pm 0.022$ & $-34.40 \pm 3.85$ \\
\hline 8 & 0.5 & 1 & ---- & 1 & 4 & 8 & 100 & $190.00 \pm 5.29$ & $0.38 \pm 0.038$ & $-45.70 \pm 5.20$ \\
\hline 9 & 0.2 & 1 & 0.2 & ---- & 4 & 8 & 100 & $138.00 \pm 7.00$ & $0.440 \pm 0.034$ & $-36.70 \pm 3.23$ \\
\hline 10 & 0.2 & 1 & 0.5 & --- & 4 & 8 & 100 & $108.33 \pm 2.08$ & $0.402 \pm 0.031$ & $-31.07 \pm 3.37$ \\
\hline 11 & 0.2 & 1 & 1.5 & ---- & 4 & 8 & 100 & $100.33 \pm 3.58$ & $0.201 \pm 0.01$ & $-22.80 \pm 3.46$ \\
\hline 12 & 0.2 & 1 & ---- & 0.2 & 4 & 8 & 100 & $223.33 \pm 7.09$ & $0.423 \pm 0.097$ & $-30.37 \pm 3.38$ \\
\hline 13 & 0.2 & 1 & --- & 0.5 & 4 & 8 & 100 & $128.00 \pm 3.00$ & $0.320 \pm 0.02$ & $-20.23 \pm 2.95$ \\
\hline 14 & 0.2 & 1 & ---- & 1.5 & 4 & 8 & 100 & $124.67 \pm 5.15$ & $0.194 \pm 0.013$ & $-10.77 \pm 0.85$ \\
\hline 15 & 0.2 & 0.0 & 1 & --- & 4 & 8 & 100 & \multicolumn{3}{|c|}{ Formation of viscous gel and no NPs were formed } \\
\hline 16 & 0.2 & 0.2 & 1 & ---- & 4 & 8 & 100 & $167.21 \pm 5.87$ & $0.182 \pm 0.002$ & $-15.23 \pm 1.65$ \\
\hline 17 & 0.2 & 0.5 & 1 & ---- & 4 & 8 & 100 & $139.00 \pm 4.34$ & $0.229 \pm 0.001$ & $-22.33 \pm 2.23$ \\
\hline 18 & 0.2 & 1.5 & 1 & ---- & 4 & 8 & 100 & $131.19 \pm 3.25$ & $0.453 \pm 0.041$ & $-32.98 \pm 3.12$ \\
\hline 19 & 0.2 & 2 & 1 & ---- & 4 & 8 & 100 & $160.43 \pm 5.43$ & $0.534 \pm 0.01$ & $-35.74 \pm 5.87$ \\
\hline 20 & 0.3 & 1 & 0.5 & ---- & 4 & 8 & 100 & $164.00 \pm 5.00$ & $0.568 \pm 0.008$ & $-41.1 \pm 5.10$ \\
\hline $21^{*}$ & 0.3 & 1 & ---- & 0.5 & 4 & 8 & 100 & $138.67 \pm 4.89$ & $0.208 \pm 0.007$ & $-37.77 \pm 3.55$ \\
\hline
\end{tabular}

${ }^{\star}$ The optimized formulation is indicated by the ${ }^{\star}$

analysis. Celecoxib-loaded NPs was prepared by the same method and celecoxib was dissolved in the organic phase in a concentration of $0.05 \%$.

\section{Optimization of NPs formulation}

To optimize our formulation, we studied the effect of several formulation parameters on final particle size, polydispersity index (PDI) and zeta potential. The variables we tested include: the type of polymer and its concentration; the type of stabilizer and its concentration; and the concentration of emulsifier (lecithin). Our criteria for selecting the optimum formula for each polymer included a small and consistent particle size and a high zeta potential. These formulations were further evaluated with regard to the effect of acetone in the organic phase, using DCM as a control. The effect of various sonication times (i.e., 0, 5, 10, $15 \mathrm{~min}$ ) and the effect of lyophilization on the particle size was studied by measuring it before and after lyophilization keeping all other parameters constant.

Characterization of plain and celecoxib-loaded NPs Measurement of particle size and zeta potential To measure particle size and zeta potential, NPs were diluted in DIW to $0.5 \mathrm{mg} / \mathrm{ml}$. Particle size and its variance, known as
PDI, was measured using photon correlation spectroscopy using a zetasizer (Nanoseries, nano-ZS, Malvern Instruments Limited, UK). The zeta potential of NPs was measured using the laser doppler velocimetry function of the zetasizer by placing the diluted sample in an electrophoretic cell until a potential of $150 \mathrm{mV}$ was established. Statistical analyses of variations in particle size and zeta potential data were performed using an unpaired t-test GraphPad Prism 5 software (GraphPad Software Inc., San Diego, CA). All experiments were performed in triplicate.

\section{Examination of the nanoparticles morphology}

The morphology of the NPs was examined with a transmission electron microscope (TEM) (JEM-2000EX II Electron Microscope, JEOL, LTD, Tokyo, Japan). Nanoparticle suspensions were diluted with DIW to yield a concentration of $0.05 \mathrm{mg} / \mathrm{ml}$ and $2 \mu \mathrm{l}$ of each suspension was placed on a 400 mesh copper grid covered with formvar (Electron Microscopy Sciences EMS, Hatfield, PA, USA). Grids were maintained in a desiccator until they were completely dry after which time they were examined by TEM.

\section{Drug loading assessment}

To determine amount of celecoxib incorporated into the NPs, 
Ibrahim et al. Journal of Pharmaceutical Technology \& Drug Research 2013,

http://www.hoajonline.com/journals/pdf/2050-120X-2-7.pdf

doi: 10.7243/2050-120X-2-7

five milligrams of celecoxibloaded NPs were weighed and dissolved in $2 \mathrm{ml}$ DMSO in a $25 \mathrm{ml}$ volumetric measuring flask and brought up to volume by absolute ethyl alcohol. The solution was assayed with a validated spectrophotometric method (-Quant universal microplate spectrophotometer Bio-Tek Instruments, Inc., USA) at $253 \mathrm{~nm}$. The total drug content of each formulation was calculated from the standard curve (with a linearity coefficient $(r)=0.999$ ). After controlling for any absorbance due to blank NPs, all measurements fell within the calibration linearity range of the standard calibration curve. Each experiment was repeated three times. The encapsulation efficiency (\% EE), drug loading $(\% \mathrm{DL})$ and $\mathrm{NP}$ yield $(\% \mathrm{Y})$ were calculated using the following equations.

$$
\begin{aligned}
& \% \mathrm{EE}=\frac{\text { Weight of celecoxib entrapped within nanoparticles }}{\text { Total celecoxib added }} \times 100 \\
& \% \mathrm{DL}=\frac{\text { Weight of celecoxib enrapped within nanoparticles }}{\text { Total weight of nanoparticles }} \times 100 \\
& \% \mathrm{Y}=\frac{\text { Total weight of nanoparticles }}{\text { Weight of polymer }+ \text { weight of celecoxib }} \times 100
\end{aligned}
$$

\section{Preparation of plain ophthalmic dosage forms}

The plain ophthalmic dosage forms that were evaluated are eye drops, a temperaturetriggered in situ gelling system, and a preformed gel. All formulations contained $0.01 \% \mathrm{w} / \mathrm{v}$ benzalkonium chloride as an anti-microbial. Eye drops were prepared by dissolving $2 \% \mathrm{w} / \mathrm{v}$ HPMC in phosphate buffered saline (PBS, $10 \mathrm{mM}, \mathrm{pH}$ 7.4). The in situ gelling system was prepared by dissolving $3 \% \mathrm{w} / \mathrm{v}$ HPMC in PBS then the solution is cooled to $4^{\circ} \mathrm{C}$ and $17 \% \mathrm{w} / \mathrm{v}$ poloxamer 188 was dissolved in such HPMC solution. The preformed eye gel was prepared by dissolving $4.5 \% \mathrm{w} / \mathrm{v} \mathrm{MC}$ in PBS and allowing it to stand for $48 \mathrm{~h}$ with periodic stirring until a clear gel was formed. Chemicals used for the preparation of plain ophthalmic formulations and their ratios were selected after preliminary experiments to determine the optimal conditions that gave clear and transparent formulation with suitable consistency. The composition of the in situ gelling system was optimized after testing several prepared in situ gelling system formulations by dropping them in an artificial tears solution at $35^{\circ} \mathrm{C} \pm 0.5$ and observing the clarity of the formed gel, gelation time and the time taken for the formed gel to dissolve [30].

\section{Preparation of ophthalmic formulation containing} celecoxib-loaded NPs

Celecoxib-loaded NPs were incorporated in the above mentioned plain ophthalmic dosage forms to give a final concentration of celecoxib equivalent to $0.1 \% \mathrm{w} / \mathrm{v}$. Each formulation was mixed well using magnetic stirrer (600 rpm) to ensure homogenous NP distribution. Subsequently each formulation was placed in a clean, dry and sterile glass container and maintained at $4^{\circ} \mathrm{C}$ until subjected to further analyses.

\section{Evaluation of ophthalmic formulations containing celecoxib-loaded NPs \\ Measurement of $\mathbf{p H}$}

One gram of each formulation was dispersed in $20 \mathrm{ml} \mathrm{DIW.}$ The $\mathrm{pH}$ was determined using a $\mathrm{pH}$ meter (Corning $\mathrm{pH}$ meter 440, Corning Incorporated, Corning, NY).

\section{Determination of formulation viscosity}

Viscosities were determined using a cone $\left(1.5^{\circ}\right)$ and plate rotary viscometer (Brookfield DVII+ programmable viscometer, Brookfield Engineering Laboratories INC., USA). Five hundred microliters of each formulation was placed on the stationary plate of the viscometer and allowed to equilibrate for $5 \mathrm{~min}$ to reach the running temperature before each measurement. The measurements were performed at $35^{\circ} \mathrm{C} \pm 0.5$. To study temperatureinduced gelation, measurements were also performed at $25^{\circ} \mathrm{C} \pm 0.5$ using the in situ gelling systems. Measurements were performed at angular velocities ramping from 0 to 200 rpm (equivalent to shear rate 0 to $768 \mathrm{~s}-1$ ) and from 200 to $0 \mathrm{rpm}$. Viscosity values were registered every $20 \mathrm{~s}$. Averages of the two readings were used to calculate the viscosity of each formulation [30]. Viscosity values at $10 \mathrm{rpm}$ were used for comparative purpose. The experiments were repeated three times and the results were calculated as mean \pm SD.

\section{Uniformity of formulation drug content}

One gram of each formulation was placed in a stoppered volumetric $100 \mathrm{ml}$ flask. Five milliliters of DMSO was added and each flask was shaken for 30 minutes. Subsequently, $50 \mathrm{ml}$ of absolute ethyl alcohol was added and flask was shaken for additional 30 minutes after which it was brought to volume using absolute ethyl alcohol. The solution was centrifuged for 15 minutes at 10,000 rpm, after which time the suspension was passed through a syringe filter (pore size $0.22 \mu \mathrm{m}$ ). The clear solution was assayed spectrophotometrically at $253 \mathrm{~nm}$ for its drug content with appropriate negative controls. The experiments were repeated three times and the results were calculated as mean \pm SD.

In vitro release study of celecoxib from ophthalmic formulations and kinetic evaluations

The release of celecoxib from different ophthalmic formulations containing drug-loaded NPs was performed using the Fast Micro-Equilibrium Dialyzer (Harvard Apparatus Co., Holliston, MA). The fast micro-equilibrium dialyzer consists of two chambers (i.e., donor chamber and acceptor chamber) each of $1500 \mu \mathrm{l}$ capacity and $1.5 \mathrm{~cm}$ diameter, separated by semipermeable regenerated cellulose membrane (Harvard Apparatus Co., Holliston, MA) with molecular weight cut-off of 25,000 Da. One hundred milligrams of the ophthalmic formulations 
containing celecoxib-loaded NPs or the control preparation (i.e., $0.1 \%$ celecoxib suspension in PBS) were placed in the donor chamber in combination with $100 \mu \mathrm{l}$ PBS. Warmed PBS $\left(1.5 \mathrm{ml}\right.$ at $\left.35^{\circ} \mathrm{C} \pm 0.5\right)$ was placed in the acceptor chamber. The two chambers were tightly closed and the dialyzer was kept in thermostatically controlled shaker $\left(35^{\circ} \mathrm{C} \pm 0.5\right.$ and $\left.50 \mathrm{rpm}\right)$. The dialyzer was placed with the donor chamber was above and the acceptor chamber below. At predetermined time intervals ranging from 30 minutes to 24 hours, the entire medium in the acceptor chamber was withdrawn and replaced by $1.5 \mathrm{ml}$ of fresh warmed PBS to ensure sink conditions. The released amount of celecoxib in the withdrawn samples from each formulation was analyzed spectrophotometrically at 253 $\mathrm{nm}$ to determine its drug content. Control experiments were performed using plain NPs incorporated in plain dosage form vehicles. The experiments were repeated three times and the concentrations were calculated from the standard curve as noted above. The release data were statistically analyzed using one-way ANOVA test followed by Tukey-Kramer multiple comparisons test [31]. Statistical calculations were carried out using GraphPad Prism 5 software (GraphPad Software Inc., San Diego, CA).

\section{In vitro evaluation of formulation cell toxicity} In vitro cytotoxicity of the formulations was evaluated with an MTT assay [32]. Briefly, HEK293 cells were seeded (4400 cells/well) into each well of 96-well plate (Costar 3596, Corning Inc., Corning, NY, USA) and allowed to incubate overnight in EMEM medium and humidified atmosphere $\left(98 \%\right.$ relative humidity, $\left.5 \% \mathrm{CO} 2,37^{\circ} \mathrm{C}\right)$. Two hundred microliters of the diluted formulations (i.e., $65 \mu \mathrm{l}$ formulation $+135 \mu$ l of EMEM medium) was added to each well. This is equivalent to $65 \mu \mathrm{g}$ celecoxib or 0.446 mg CS-NPs or $0.487 \mathrm{mg}$ ALG-NPs. After a $24 \mathrm{~h}$ incubation, the formulation was replaced with $160 \mu \mathrm{l}$ of growth medium. Forty microliters of MTT reagent $(5 \mathrm{mg} / \mathrm{ml})$ was added to each well. After $4 \mathrm{hrs}$ of incubation at $37^{\circ} \mathrm{C}$, the medium was replaced with $200 \mu \mathrm{IDMSO}$ as a formazan solvent. The plate was then shaken for $15 \mathrm{~min}$. Optical absorbance was measured at $570 \mathrm{~nm}$ with the use of a microplate reader (-Quant Universal Microplate Spectrophotometer, Bio-Tek Instruments, Inc.) and converted to percent cell viability relative to the control (untreated) cells. Statistical analysis of the percent cell viability data was performed using a one-way ANOVA with Tukey- Kramer multiple comparison tests [31]. Each experiment was done in six replicates.

\section{Results and discussion}

The goal of our investigation was to devise a non-invasive sustained release topical ophthalmic celecoxib formulation to overcome the drawbacks of systemic dosage. To achieve this goal, we optimized the preparation of two NPs synthesized from natural polymers and three delivery formulations.

\section{Characterization and optimization of plain nanoparticles}

Cationic CS-NPs and anionic ALG-NPs were prepared using a spontaneous emulsification solvent diffusion method. To optimize the NP formulations, the effect of various formulation parameters on the particle size and zeta potential were studied. The method of production is very simple, as the production of nano-sized particles required only simple magnetic stirring followed by sonication without successive mechanical treatment. The optimized NPs formulations that were chosen for drug incorporation and preparation of our ophthalmic formulation were selected because they had the lowest particle size and PDI - which would allow them to pass through biological barriers - and the highest zeta potential to achieve the highest stability in aqueous systems.

\section{Effect of polymer and its concentration}

Increasing the polymer concentration of either CS or ALG led to an increase in the viscosity of the preparation medium, which in turn increased the particle size and the size distribution of the resultant NPs (Tables 1 and 2, Formulations 1-8). It is possible that the increased viscosity of the preparation medium caused enlarged organic phase droplets to be dispersed in the aqueous phase. This process may then have interfered with the interfacial hydrodynamic phenomenon that is responsible for spontaneous emulsification process [33]. Moreover, at the same concentration, CS-NPs had a larger particle size than ALG-NPs. This may be due to the higher viscosity of the CS solution than ALG solution because of the higher molecular weight of CS used. CS-NPs also possessed a positive charge due to the presence of amine groups on its surface. This positive charge was enhanced by increasing the polymer concentration. The negative charge of the ALG-NPs is due to the presence of the free carboxylic groups on its surface. Like CS-NPs, the charge of the ALG-NPs was enhanced by increasing the polymer concentration used to produce the NPs.

\section{Effect of stabilizer and its concentration}

Increasing the stabilizer concentration with either Poloxamer 188 or PVA decreased the particle size of the NPs and improved its size distribution (Tables 1 and 2, Formulations 2, 6 and 9-14). This may be due to the fact that the presence of the stabilizer in the external aqueous phase stabilized the emulsion droplets against coalescence. This stabilization effect became more dominant at higher stabilizer concentrations, which decrease the size and PDI of NPs. These results are in agreement with those obtained by Mao et al., who reported that increasing PVA concentration caused a marked decrease in the particle size and PDI of PLGA microspheres loaded with fluorescein isothiocyanatelabeled dextrans [34]. The stabilizer concentration also had an inverse relationship with the zeta potential, which 
could be attributed to the shielding effect. This property is due to stabilizer that is incorporated in the thin film on the surface of the NPs, which may partially mask the surface charge. These results are in agreement with those obtained by Sahoo et al., who demonstrated that increasing PVA concentration from $0.5 \%$ to $5 \%$ led to a decrease in the negative zeta potential of PLGA-NPs due to the increase in the residual amount of PVA on the particle surface which acted as a shield that mask the negative charge of PLGANPs [35]. Also Redhead et al., reported a similar reduction in the negative zeta potential of PLGA-NPs after coating with Poloxamer 407 and Poloxamine 908, which they attributed to the shielding effect exerted by the stabilizers [36]. We found that the zeta potential of NPs prepared with PVA were slightly lower than that of Poloxamer 188, suggesting that the shielding effect of PVA was greater than that of poloxamer 188. This may be because PVA was more strongly attached to the NPs surface than Poloxamer, which made it more difficult to remove during washing resulting in a stronger shielding effect and net higher surface coverage [37].

\section{Effect of lecithin and its concentration}

The particle size data in Table 1 (Formulations 2 and 15-19) and Table 2 (Formulations 6 and 15-19) demonstrated that lecithin is necessary for NP formation because without lecithin (Formulation 15 in both Tables 1 and 2), the preparation medium was very viscous gel that inhibited NP formation. In fact, we observed that the effect of lecithin on the particle size of NPs is a biphasic process. Specifically, increasing lecithin concentration from $0.0 \%$ to $1 \%$ led to a decrease in the particle size for both CS-NPs and ALG-NPs, but a further increase in lecithin concentration above $1 \%$ led to increase in NPs particle size. Increasing lecithin concentration from $0.0 \%$ to $1 \%$ led to an increase in its emulsification capacity that encourage the spontaneous emulsification process yielding smaller particle size. Increasing the lecithin ratio above $1 \%$ (i.e., optimal emulsifier concentration at which saturated emulsifier packing located at the surface of NPs) may have led to deposition of more lecithin in the interfacial film formed on o/w interface during emulsification which in turn led to an increase in the size of NPs. The lecithin concentration had an inverse relationship with the positive zeta potential values of CS-NPs, and a direct relation with the negative zeta potential of the ALG-NPs. As previously stated, the higher the lecithin concentration, the higher the lecithin content in the thin film located on the surface of NPs. Since lecithin carried a negative charge, the positive charges of CS-NPs were partially neutralized by the negative charge of lecithin. Thus, increasing lecithin concentration led to a decrease in the positive zeta potential of CS-NPs, while increasing the negative one of ALG-NPs [38].

\section{Effect of acetone in the organic phase}

The data presented in Table $\mathbf{3}$ demonstrate that acetone is a very important factor to produce smaller NPs. As shown in the table, NPs prepared without acetone have a larger particle size (552 and $395 \mathrm{~nm}$ for CS-NPs and ALG-NPs, respectively) compared to (107 and $138 \mathrm{~nm}$ for CSNPs and ALG-NPs, respectively) when using acetone. The presence of acetone in the organic phase facilitates the formation of smaller NPs without successive mechanical treatment. Because acetone is miscible with both DCM and water, it decreases the interfacial tension during the emulsification process resulting in a smaller particle size. In addition, the turbulence of the interface caused by the rapid acetone diffusion from the organic phase to the aqueous phase increases the area of the interface due to the spontaneous division of organic droplets into smaller ones. These smaller droplets still contain acetone that undergoes additional diffusion to the surrounding aqueous phase, thus producing additional interface turbulence. This step was repeated many times in our investigation, resulting in the formation of smaller NPs each time. These results agree with those obtained by Niwa et al., who reported that the presence of acetone in the organic phase is an essential factor for forming nano-sized spheres [27]. Also, El-Shabouri reported that acetone is very important in producing particles in the nano-size range, while its absence produced particles with average diameter greater than $1.2 \mu \mathrm{m}$ [28]. In this investigation, there were significant decreases in zeta potential of both cationic and anionic NPs prepared in absence of acetone when compared with those prepared in the presence of acetone $(p<0.05)$ this may be due to changing in the arrangement of the surfactants molecules on the NPs surface as a result of absence of acetone.

\section{Effect of sonication time}

Sonication is very important variable in the production of NPs of small size with a narrow size distribution, as exerting energy is a fundamental step in emulsification process. Our results presented in Table 3 show that without sonication, the NPs were of a larger particle size (682 and $485 \mathrm{~nm}$ for CSNPs and ALG-NPs, respectively) with high PDI values (0.971 and 0.724 for CSNPs and ALG-NPs, respectively). Increasing sonication time from 0 to $10 \mathrm{~min}$ led to a significant decrease in both particle size and PDI $(p<0.0001)$. These results are in agreement with those obtained by Mainardes and Evangelista, who reported that increasing the sonication time from 1 to 20 min greatly decreased the particle size and improved the size distribution of praziquantel-loaded PLGA-NPs [39]. However, increasing the sonication time to $15 \mathrm{~min}$ had a reverse effect as the particle size was slightly increased. This may be due to the aggregation of very small particles that resulted from prolonged sonication time to form larger ones. These results are in accordance with those observed by Tripathi et al., who reported that 
Ibrahim et al. Journal of Pharmaceutical Technology \& Drug Research 2013, http://www.hoajonline.com/journals/pdf/2050-120X-2-7.pdf

doi: 10.7243/2050-120X-2-7

Table 3. Effect of different formulation parameters on particle size, PDI and zeta potential of optimized formulae.

\begin{tabular}{|c|c|c|c|c|}
\hline \multirow{2}{*}{ Aspect } & & \multicolumn{3}{|c|}{ Evaluation $($ mean $\pm S D)$} \\
\hline & & $\begin{array}{l}\text { Particle Size } \\
(\mathrm{nm})\end{array}$ & (PDI) & $\begin{array}{l}\text { Zeta Potential } \\
(\mathrm{mV})\end{array}$ \\
\hline \multirow{2}{*}{$\begin{array}{c}{ }^{*} \text { Optimized } \\
\text { formulae }\end{array}$} & CS-NPs & $107.33 \pm 5.53$ & $0.211 \pm 0.008$ & $35.30 \pm 4.20$ \\
\hline & ALG-NPs & $138.67 \pm 4.89$ & $0.208 \pm 0.007$ & $-37.77 \pm 3.55$ \\
\hline \multirow[t]{2}{*}{ Effect of acetone } & $\begin{array}{l}\text { CS-NPs without } \\
\text { acetone }\end{array}$ & $552.00 \pm 21.00$ & $0.327 \pm 0.032$ & $25.50 \pm 2.6$ \\
\hline & $\begin{array}{l}\text { ALG-NPs without } \\
\text { acetone }\end{array}$ & $395.00 \pm 13.00$ & $0.535 \pm 0.04$ & $-26.90 \pm 3.46$ \\
\hline \multirow[t]{3}{*}{ CS-NPs } & No sonication & $682.44 \pm 32.18$ & $0.971 \pm 0.01$ & $36.21 \pm 3.61$ \\
\hline & 5 min sonication & $190.11 \pm 11.26$ & $0.442 \pm 0.005$ & $33.52 \pm 2.58$ \\
\hline & 15 min sonication & $118.23 \pm 2.27$ & $0.202 \pm 0.007$ & $35.7 \pm 1.70$ \\
\hline \multirow[t]{3}{*}{ ALG-NPs } & No sonication & $484.76 \pm 23.66$ & $0.724 \pm 0.04$ & $-37.89 \pm 1.74$ \\
\hline & 5 min sonication & $198.72 \pm 13.12$ & $0.333 \pm 0.02$ & $-40.21 \pm 2.11$ \\
\hline & 15 min sonication & $145.35 \pm 4.22$ & $0.299 \pm 0.016$ & $-35.37 \pm 3.60$ \\
\hline \multirow{2}{*}{$\begin{array}{c}\text { Effect of } \\
\text { lyophilization }\end{array}$} & $\begin{array}{l}\text { CS-NPs before } \\
\text { lyophilization }\end{array}$ & $110.33 \pm 2.33$ & $0.231 \pm 0.015$ & $39.24 \pm 5.23$ \\
\hline & $\begin{array}{l}\text { ALG-NPs before } \\
\text { lyophilization }\end{array}$ & $140.66 \pm 3.26$ & $0.210 \pm 0.005$ & $-41.35 \pm 7.68$ \\
\hline
\end{tabular}

* Data of the optimized formulae were obtained in the presence of acetone, 10 min sonication and after lyophilization.

$20 \mathrm{~min}$ is the ideal sonication time for their formulation and sonication for $24 \mathrm{~min}$ increased the particle size of rifampicin-loaded PLGA-NPs [40].

\section{Effect of lyophilization}

Lyophilization is performed to remove water from the formulation and therefore improve NP stability upon storage. The process of freeze-drying is stressful and hence a cryoprotectant is added in the process in order to maintain the particle size and help NP reconstitution [41]. Our data presented in Table 3 demonstrate that the lyophilization process has no significant effect on the particle size or PDI of NPs made from either CS or ALG ( $p>0.05)$. This indicated the cryoprotective efficiency of trehalose when used in a concentration of $5 \%$ to maintain the average particle size of NPs during freeze-drying process. Similar observations were reported by Sonaje et al., [42] and Hafner et al., [43]. Regarding NPs zeta potential, it was found that there was a minor decrease in zeta potential values after lyophilization for both positively charged CSNPs and negatively charged ALG-NPs. This may be explained by the NP surface masking the effect contributed by the cryoprotectant due to the hydrogen bonding between the $(\mathrm{OH})$ groups of trehalose and NPs surface or due to the rearrangement of the surfactants (lecithin, PVA and Poloxamer 188) molecules on the NPs surface during freeze drying process. These results are in accordance with those obtained by De Chasteigner et al., who reported that there is a considerable decrease in the negative zeta potential of itraconazole-loaded poly ( $($-caprolactone) NPs after freeze drying using $10 \%$ sucrose as cryoprotectant [44].

\section{Characterization of celecoxib-loaded nanoparticles} Particle size and zeta potential

Our data presented in Table 4 demonstrate that there was a non-significant increase in the mean particle size of CS-NPs $(p>0.05)$ and a significant increase in that of ALG-NPs after incorporation of celecoxib, compared to the mean particle size of the plain NPs $(p<0.05)$ without any significant effect on the NPs zeta potential ( $p>0.05)$. Although there was an increase in the particle size of the drug loaded NPs, its size is still in the reasonable range required for an accepted in vivo study as it is known that NPs less than $200 \mathrm{~nm}$ are considered acceptable for passive drug targeting $[45,46]$.

\section{Celecoxib encapsulation efficiency}

Our results (Table 4) demonstrate that the encapsulation efficiency of celecoxib was very high (89.88 and $75.38 \%$ for CS-NPs and ALG-NPs, respectively) with a final drug loading of 14.57 and $13.34 \%$ for CS-NPs and ALG-NPs, respectively. Since, celecoxib is a very poorly water soluble drug (the measured celecoxib solubility in deionized water is $6.98 \pm 0.021 \mu \mathrm{g} / \mathrm{ml}$ at $25^{\circ} \mathrm{C} \pm 0.5$ ), so it was preferentially partitioned in the organic phase during spontaneous 


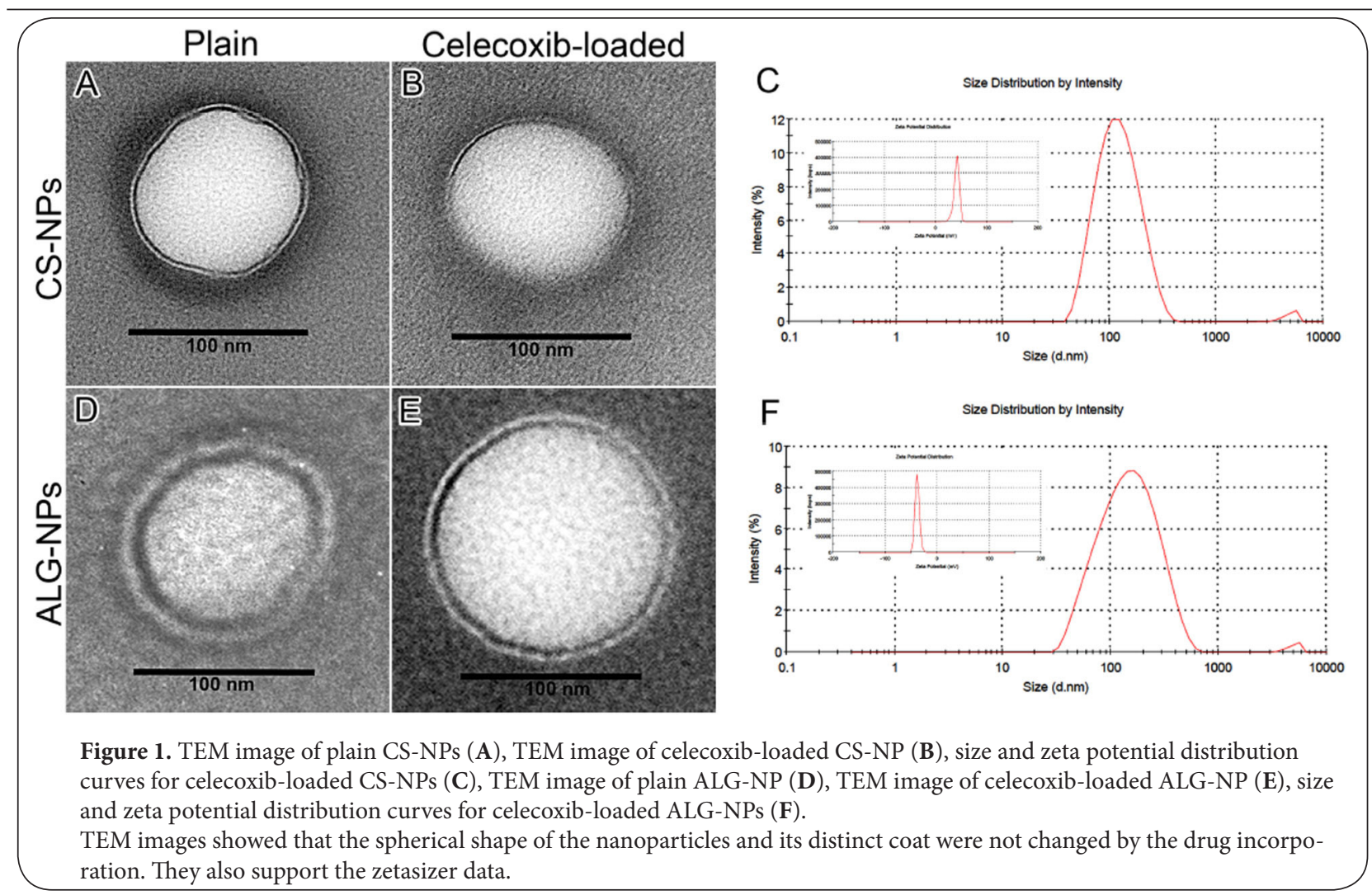

Table 4. Characteristics of optimized celecoxib-loaded NPs.

\begin{tabular}{lll}
\hline \multirow{2}{*}{ Parameters } & \multicolumn{2}{l}{ Evaluation $($ mean \pm SD) } \\
\cline { 2 - 3 } & CS-NPs & ALG-NPs \\
\hline Particle Size $(\mathrm{nm})$ & $113.33 \pm 4.08$ & $154.67 \pm 5.06$ \\
PDI & $0.215 \pm 0.01$ & $0.225 \pm 0.01$ \\
Zeta Potential $(\mathrm{mV})$ & $36.92 \pm 3.38$ & $-36.50 \pm 4.70$ \\
$\%$ EE & $89.88 \pm 4.17$ & $75.38 \pm 2.98$ \\
$\% \mathrm{DL}$ & $14.57 \pm 0.68$ & $13.34 \pm 0.53$ \\
$\% \mathrm{Y}$ & $88.12 \pm 4.11$ & $80.73 \pm 7.31$ \\
\hline \% EE is the percentage encapsulation efficiency. \\
\% DL is the percentage drug loading. \\
\% Y is the percentage of NPs yield.
\end{tabular}

emulsification step (the measured celecoxib partition coefficient in $\mathrm{n}$-octanol/water system is $3.418 \pm 0.082$ at $25^{\circ} \mathrm{C} \pm 0.5$ ) and consequently, only a small amount of celecoxib was lost in the aqueous phase. Also, the small particle size achieved in our optimized formulations greatly improved the celecoxib encapsulation efficiency. The use of acetone, which is a highly diffusible and volatile solvent, also had a positive effect on increasing celecoxib encapsulation efficiency. Upon organic phase injection into the aqueous phase during NPs preparation, acetone was removed rapidly leaving the poorly water-soluble drug within NPs away from the external aqueous phase. These results are in accordance with those obtained by Kim et al., who reported that there was an improvement in the encapsulation efficiency of celecoxib in PLGA NPs when using acetone as a solvent compared to other solvents such as dimethylformamide, dimethylsulfoxide, 1,4-dioxane and dimethylacetamide [47].

\section{Nanoparticle surface morphology}

The TEM images (Figure 1) of both plain and celecoxibloaded CS-NPs and ALG-NPs supports the particle size data obtained by the zetasizer. Morphologically, the NPs have a distinct spherical shape with a solid dense polymer core surrounded by evenly distributed coat that may be comprised of lecithin and NPs stabilizer (PVA or Poloxamer 188). Drug incorporation did not affect the shape of the NPs.

\section{Characterization of formulations containing celecoxib-loaded NPs}

Characterization of ophthalmic formulations (i.e., eye drops, in situ gelling system and preformed gel) containing either celecoxib-loaded CS-NPs or ALG-NPs were evaluated as follows:

\section{$\mathrm{pH}$ of the formulations}

The $\mathrm{pH}$ of eye tears is 7.4 and due to its natural buffering capacity, it can tolerate ophthalmic formulations in a wide $\mathrm{pH}$ range from 3.5 to 8.5. Moreover, the typical ophthalmic dose is 1 or 2 drops, which can be easily accommodated by the eye and is rapidly restored to its normal $\mathrm{pH}$ value by the intrinsic buffering system [48]. Our data presented in 


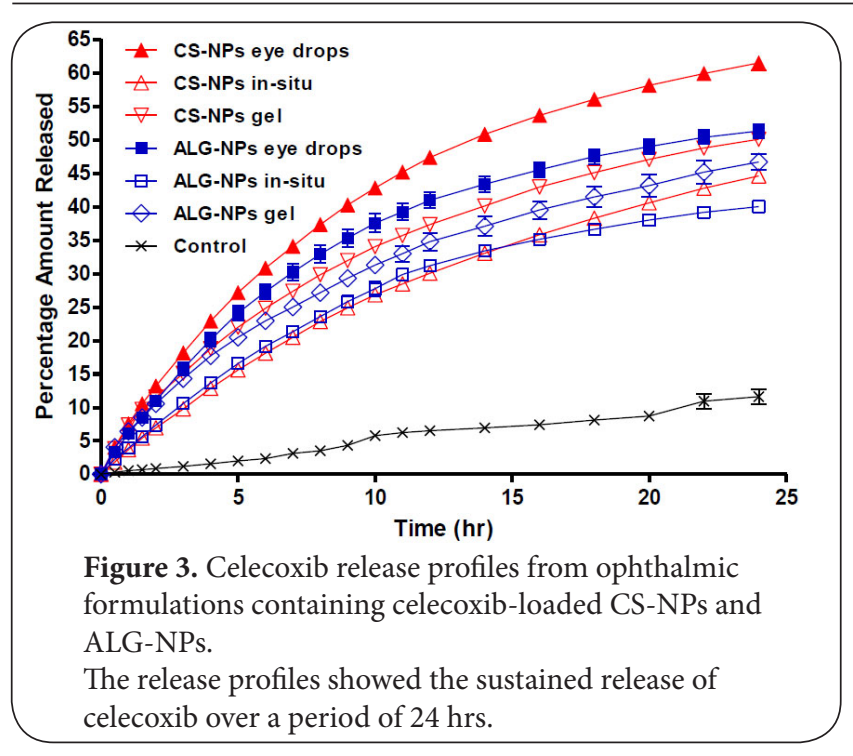

by increasing the temperature of the measurement from a non-physiological temperature $\left(25^{\circ} \mathrm{C}\right)$ to a physiological temperature $\left(35^{\circ} \mathrm{C}\right)$, which suggests that our in situ gelling system will undergo sol-gel transition upon instillation into the eye.

\section{Drug content}

Table 5 illustrates that the actual celecoxib content of the prepared ophthalmic formulations ranged from 98.33 to $102.11 \%$ of that loaded into celecoxib-loaded NPs. These result showed that the deviation of the drug contents from the originally added active constituents are less than $\pm 5 \%$, which complies with the USP official requirement [49]. Also the small values of the standard deviation indicate a uniform distribution of the celecoxib-loaded NPs within the ophthalmic formulations vehicles.

\section{In vitro release of celecoxib and its kinetics}

In vitro release studies were conducted for only $24 \mathrm{~h}$, as the tested formulations were intended for topical ophthalmic use. Blank formulations did not have any significant absorbance at $253 \mathrm{~nm}$. The release profiles as shown in Figure 3 confirmed that it is possible to prepare sustainedrelease topical ophthalmic formulations containing either celecoxib-loaded bioadhesive positively charged CSNPs or negatively charged ALG-NPs. All the formulations possessed a sustained drug release rate that was free from any burst release that may cause toxicity. Burst release is a characteristic of drug released from monolithic NP systems due to the rapid dissolution of the drug molecules located on or near the NP surface into the surrounding fluid. In our study, the absence of burst release may be due to two factors. The first is that the NPs are not suspended directly in the dissolution medium; rather they are dispersed in its dosage form vehicles (i.e., eye drops, in situ gelling system or gel). Therefore, once the drug is released from the NPs, it dispersed in the dosage form prior to being released to the medium. This step-wise sequence sustained the release of drug and decreased the burst effect. The second factor is the presence of a coat around the NPs that was confirmed by TEM (Figure 1). This coat shielded the NP surface and prevented the rapid burst release upon dilution with the release medium. In the literature, many studies coat NPs using certain coating materials to decrease or prevent the burst release. Huang et al., reported that coating of NPs with gelatin reduced the initial burst release of propranolol $\mathrm{HCl}$ and lidocaine from PLA/PEG NPs [52]. Also, Garcia-Fuentes et al., reported that coating of lipid NPs with chitosan inhibit the burst release of salmon calcitonin [53]. Budhian et al., showed that chitosan coating of PLGA-NPs reduced the burst release of haloperidol [54].

The percentage of the cumulative amount of celecoxib released after $24 \mathrm{~h}$ from CS-NPs preparations was 61.5, 50.1 and $44.6 \%$ for eye drops, preformed gel and the in situ gelling system, respectively. From ALG-NPs preparations, the cumulative release was $51.3,46.7$ and $40.1 \%$ for eye drops, preformed gel and in situ gelling system, respectively. The release of celecoxib from all preparations was significantly different from that of the control preparation $(p<0.001)$, as the control preparation showed an irregular uncontrolled release pattern that is only governed by the low celecoxib solubility in the release medium (the measured celecoxib solubility in PBS is $6.18 \pm 0.043 \mu \mathrm{g} / \mathrm{ml}$ at $25^{\circ} \mathrm{C} \pm 0.5$ ). The celecoxib release profiles from CSNPs preparations were significantly different from each other $(p<0.01)$. Similarly, for ALGNPs preparations, the celecoxib release profiles were also statistically different from each other $(p<0.05)$. CS-NP preparations of like kind showed significantly higher celecoxib release profiles than ALG-NPs formulations $(p<0.05)$, These higher release rates of the CS preparations may be due to the smaller particle size of CS-NPs, as the smaller the particle size the higher the surface area available for drug release and thus the higher the release rate [55]. Also, the dosage form vehicles played an important role in controlling the celecoxib release rate, as the release rates of the formulations were in the following order: eye drops $>$ preformed gel $>$ in situ gelling system. This may be due to the difference in their viscosities upon dilution with $\mathrm{PBS}$ at $35^{\circ} \mathrm{C}$, as the higher the viscosity, the slower the release rate [56].

In order to determine the kinetic model that best describes the release mechanism, the in vitro release data were analyzed according to zero-order, first-order and Higuchi diffusion models. The model with the highest correlation coefficient was selected as the best fit [57]. We used the Korsmeyer-Peppas semi-empirical model for additional in depth analysis [58], where the value of the release exponent is determined by the release mechanism and thus can be used to characterize it [59].

Results of release kinetic analyses (Table 6) showed that celecoxib released from all the formulations followed the 
Ibrahim et al. Journal of Pharmaceutical Technology \& Drug Research 2013, http://www.hoajonline.com/journals/pdf/2050-120X-2-7.pdf

Table 6. In vitro release kinetics of celecoxib.

\begin{tabular}{|c|c|c|c|c|c|c|c|c|}
\hline & \multirow[t]{2}{*}{ Formulation } & \multicolumn{3}{|c|}{$\begin{array}{l}\text { Correlation Coefficient } \\
\left(\mathbf{r}^{2}\right)\end{array}$} & \multirow{2}{*}{$\begin{array}{l}\text { Release } \\
\text { Mechanism }\end{array}$} & \multicolumn{2}{|c|}{ Korsmeyer-Peppas } & \multirow{2}{*}{$\begin{array}{l}\text { Drug } \\
\text { transport } \\
\text { mechanism }\end{array}$} \\
\hline & & Zero & First & Higuchi & & $\mathbf{n}$ & $\mathbf{r}^{2}$ & \\
\hline & Control & 0.9106 & 0.8111 & 0.8526 & Dissolution & 0.9711 & 0.9659 & $\begin{array}{l}\text { Super Case } \\
\text { Transport II }\end{array}$ \\
\hline \multirow{3}{*}{$\sum_{n}^{\infty}$} & Eye Drops & 0.9040 & 0.6917 & 0.9815 & Diffusion & 0.6986 & 0.9809 & Non-Fickian \\
\hline & In-Situ Gellig & 0.9573 & 0.7245 & 0.9839 & Diffusion & 0.8149 & 0.9901 & Non-Fickian \\
\hline & Performed Gel & 0.9107 & 0.7107 & 0.9816 & Diffusion & 0.6501 & 0.9782 & Non-Fickian \\
\hline \multirow{3}{*}{ 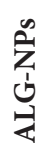 } & Eye Drops & 0.8686 & 0.6559 & 0.9602 & Diffusion & 0.7141 & 0.9595 & Non-Fickian \\
\hline & In-Situ Gellig & 0.9079 & 0.6909 & 0.9756 & Diffusion & 0.7661 & 0.9772 & Non-Fickian \\
\hline & Performed Gel & 0.9059 & 0.7255 & 0.9746 & Diffusion & 0.6403 & 0.9856 & Non-Fickian \\
\hline
\end{tabular}

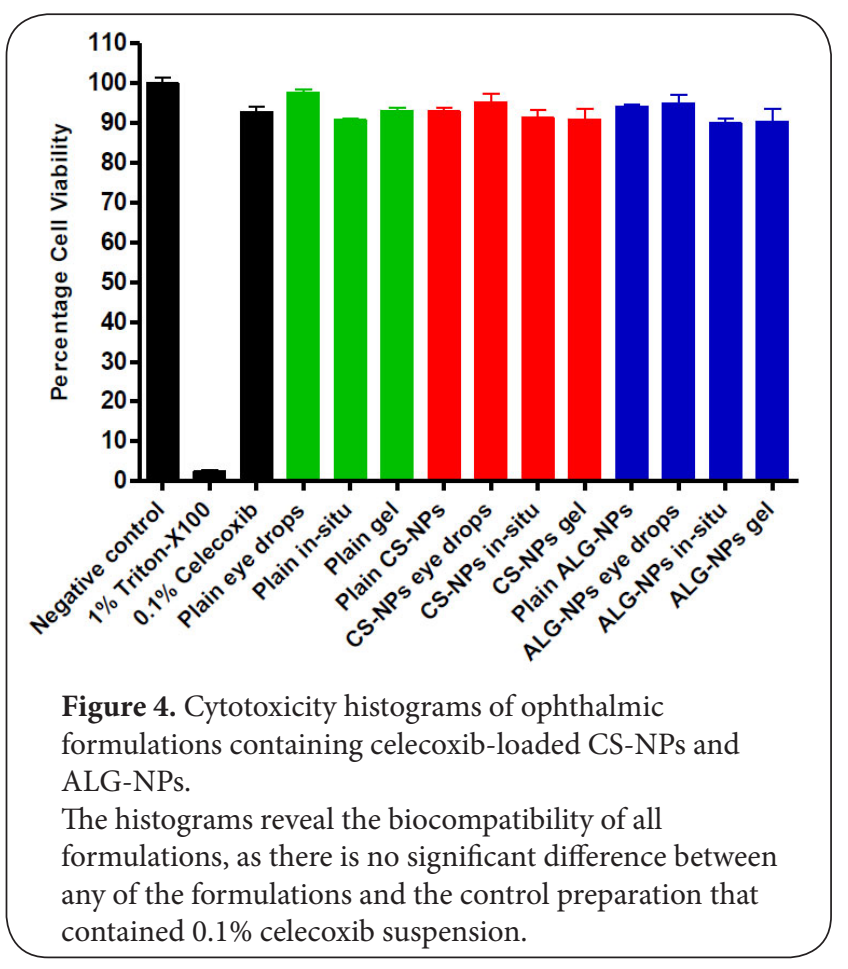

Higuchi model, suggesting that the release mechanism is diffusion. In contrast, the control preparation followed zero-order kinetics, that suggesting dissolution of celecoxib from its crystals. Further analysis of the release data using the Korsmeyer-Peppas equation showed that the release exponents (n) for all formulation ranged from 0.45 to 0.89 , which indicated that they exhibited non-Fickian or anomalous diffusion. Therefore, the drug release from the formulation was not by a pure diffusion mechanism, but was rather a mixture of both diffusion from the NPs and erosion of the polymers. The value of $(n)$ for the control preparation was 0.9711 , which indicates a super case transport II suggesting that the release is governed only by erosion of celecoxib crystals during its dissolution [59].

\section{In vitro cytotoxicity}

To evaluate possible cell toxicity of the formulations, we used a volume of $65 \mu \mathrm{l}$, which is the highest estimated value for an ophthalmic dose, as the volume of a single drop obtained from multi-dose eye drops bottles was reported to range from 33.8 to $63.4 \mu \mathrm{l}[\mathbf{6 0}]$. The HEK293 cell line was selected to test the in vitro cytotoxicity of our formulations due to its high sensitivity toward toxic materials. This characteristic has made this cell line widely used by a large number of researchers to estimate the in vitro cell toxicity of their pharmaceutical preparations before in vivo testing [32,61-64]. Figure 4 shows that all tested formulations - plain dosage form vehicles, plain NPs, celecoxib suspension, CS-NPs formulations and ALGNPs formulations - were not toxic, as the cell viability of all formulations ranged from 89.9 to $97.7 \%$. These results showed no statistically significant differences $(p>0.05)$ compared to the control preparation containing $0.1 \%$ celecoxib suspension. Therefore, the minimal toxicity that we measure may be due to the drug itself, rather than the formulations. Also the percent cell viability of all formulations showed high statistically significant differences $(p<0.001)$ compared to the positive control containing $1 \%$ of the cytotoxic agent Triton-X 100. This may be due to the fact that all the polymers used in our formulations either for preparation of the vehicles [65] or the NPs $[1,9]$ possessed an excellent biocompatibility.

\section{Conclusions}

This paper describes the preparation and evaluation of new topical ophthalmic sustainedrelease dosage forms containing celecoxib-loaded CS or ALG NPs prepared by a spontaneous emulsification solvent diffusion method. The optimized NP formulations had desirable particle sizes, zeta potentials and surface morphology. The prepared formulations possessed $\mathrm{pH}$ and viscosity values that are compatible with the eye and have uniform drug contents that complied with the USP official requirement. In vitro release data of all ophthalmic formulations showed a sustained release, free of any burst effect; the release profiles follow a Higuchi non-fickian diffusion mechanism. The in vitro cytotoxicity results revealed that all prepared formulations were non- 
toxic. Statistical analysis of cytotoxicity results showed that there were no statistically significant differences between the formulations and the control preparation that contained $0.1 \%$ celecoxib suspension. Although both CS- and ALG-NPs possessed bioadhesive properties, we suggest that CS-NP preparations will be more efficacious than ALG-NPs due to the positive charge carried by CS. This feature improves its adherence to the negatively charged eye surface, resulting in longer ocular contact time and therefore more sustained effect. Because these formulations are intended for topical use, CS is preferred over ALG due to its penetration enhancing properties [10]. In vivo studies and accelerated stability studies of the ophthalmic formulations stored at three different temperatures $\left(30,35\right.$ and $45^{\circ} \mathrm{C}$ ) for six months are in progress. Our investigation has determined the optimal formulations for sustained delivery of celecoxib to treat conditions of the eye.

\section{Competing interests}

The authors declare that they have no competing interests.

\section{Authors' contributions}

$\mathrm{MMJ}$ is the corresponding author who contributed to the overall study design, as well as drafting, organizing, and revising the manuscript. MMI was solely responsible for the practical work of this study. Further, he performed the statistical analysis of data and he has been involved in drafting, organizing the manuscript. AHA and OAS have a contribution toward the conception and design of the study. All authors have read and approved this version of the final manuscript.

\section{Acknowledgements and funding}

The authors thank Drs. Shankar Swaminathan and Mallika Palamoor for their critical reading of this manuscript. They also thank Dr. Joel Bumgardner for the use of his viscometer. This study was supported by The Egyptian Government Joint Supervision Progam, The University of Tennessee Research Foundation and an Unrestricted Grant from Research to Prevent Blindness, New York, NY.

\section{Publication history}

Received: 29-Nov-2012 Revised: 14-Dec-2012

Re-Revised: 6-Jan-2013 Accepted: 23-Jan-2013

Published: 11-Feb-2013

\section{References}

1. De $S$ and Robinson D: Polymer relationships during preparation of chitosan-alginate and poly-I-lysine-alginate nanospheres. J Control Release 2003, 89:101-12. | Article | PubMed

2. Alonso MJ: Nanomedicines for overcoming biological barriers. Biomed Pharmacother 2004, 58:168-72. | Article | PubMed

3. Bourlais $C L$, Acar L, Zia H, Sado PA, Needham T and Leverge R: Ophthalmic drug delivery systems--recent advances. Prog Retin Eye Res 1998, 17:33-58. | Article | PubMed

4. Smolin G, Okumoto M, Feiler S and Condon D: Idoxuridine-liposome therapy for herpes simplex keratitis. Am J Ophthalmol 1981, 91:220-5. | Article | PubMed

5. Losa C, Calvo P, Castro E, Vila-Jato JL and Alonso MJ: Improvement of ocular penetration of amikacin sulphate by association to poly(butylcyanoacrylate) nanoparticles. J Pharm Pharmacol 1991, 43:548-52. | Article | PubMed
6. Losa C, Marchal-Heussler L, Orallo F, Vila Jato JL and Alonso MJ: Design of new formulations for topical ocular administration: polymeric nanocapsules containing metipranolol. Pharm Res 1993, 10:80-7. | Article | PubMed

7. Motwani SK, Chopra S, Talegaonkar S, Kohli K, Ahmad FJ and Khar RK: Chitosan-sodium alginate nanoparticles as submicroscopic reservoirs for ocular delivery: formulation, optimisation and in vitro characterisation. Eur J Pharm Biopharm 2008, 68:513-25. | Article | PubMed

8. Shahidi F and Abuzaytoun R: Chitin, chitosan, and co-products: chemistry, production, applications, and health effects. Adv Food Nutr Res 2005, 49:93-135. | Article | PubMed

9. Alonso MJ and Sanchez A: The potential of chitosan in ocular drug delivery. J Pharm Pharmacol 2003, 55:1451-63. | Article | PubMed

10. De la Fuente M, Ravina M, Paolicelli P, Sanchez A, Seijo B and Alonso $\mathrm{MJ}$ : Chitosan-based nanostructures: a delivery platform for ocular therapeutics. Adv Drug Deliv Rev 2010, 62:100-17. | Article | PubMed

11. Varum KM, Myhr MM, Hjerde RJ and Smidsrod O: In vitro degradation rates of partially $\mathrm{N}$-acetylated chitosans in human serum. Carbohydr Res 1997, 299:99-101. | Article | PubMed

12. Temel $A$, Kazokoglu $H$ and Taga $Y:$ Tear lysozyme levels in contact lens wearers. Ann Ophthalmol 1991, 23:191-4. | PubMed

13. Rabea El, Badawy ME, Stevens CV, Smagghe G and Steurbaut W: Chitosan as antimicrobial agent: applications and mode of action. Biomacromolecules 2003, 4:1457-65. | Article | PubMed

14. De Campos AM, Sanchez A and Alonso MJ: Chitosan nanoparticles: a new vehicle for the improvement of the delivery of drugs to the ocular surface. Application to cyclosporin A. Int J Pharm 2001, 224:159-68. | Article | PubMed

15. Rajaonarivony $M$, Vauthier $C$, Couarraze $G$, Puisieux F and Couvreur $P$ : Development of a new drug carrier made from alginate. J Pharm Sci 1993, 82:912-7. | Article | PubMed

16. Bodmeier $\mathrm{R}$ and Wang J: Microencapsulation of drugs with aqueous colloidal polymer dispersions. J Pharm Sci 1993, 82:191-4. | PubMed Sechoy O, Tissie G, Sebastian C, Maurin F, Driot JY and Trinquand C: A new long acting ophthalmic formulation of carteolol containing alginic acid. Int J Pharm 2000, 207:109-16. | Article | PubMed

17. Schalnus $R$ : Topical nonsteroidal anti-inflammatory therapy in ophthalmology. Ophthalmologica 2003, 217:89-98. | Article | PubMed

18. Sechoy O, Tissie G, Sebastian C, Maurin F, Driot JY, Trinquand C: A new long acting ophthalmic formulation of carteolol containing alginic acid. Int J Pharm 2000, 207:109-116 | Article |PubMed

19. Kim SJ, Flach AJ and Jampol LM: Nonsteroidal anti-inflammatory drugs in ophthalmology. Surv Ophthalmol 2010, 55:108-33. | Article I PubMed

20. Johnson El, Dunlop ME and Larkins RG: Increased vasodilatory prostaglandin production in the diabetic rat retinal vasculature. Curr Eye Res 1999, 18:79-82. | Article | PubMed

21. Tong CT, Howard SA, Shah HR, Van Quill KR, Lin ET, Grossniklaus HE and O'Brien JM: Effects of celecoxib in human retinoblastoma cell lines and in a transgenic murine model of retinoblastoma. $B r J$ Ophthalmol 2005, 89:1217-20. | Article | PubMed Abstract | PubMed Full Text

22. Bauer AM, Fiehn $C$ and Becker MD: Celecoxib, a selective inhibitor of cyclooxygenase 2 for therapy of diffuse anterior scleritis. Am J Ophthalmol 2005, 139:1086-9. | Article | PubMed

23. Ayalasomayajula SP and Kompella UB: Retinal delivery of celecoxib is several-fold higher following subconjunctival administration compared to systemic administration. Pharm Res 2004, 21:1797-804. | Article | PubMed

24. Amrite AC, Ayalasomayajula SP, Cheruvu NP and Kompella UB: Single periocular injection of celecoxib-PLGA microparticles inhibits diabetes-induced elevations in retinal PGE2, VEGF, and vascular leakage. Invest Ophthalmol Vis Sci 2006, 47:1149-60. | Article | PubMed Abstract | PubMed Full Text 
25. Ayalasomayajula SP and Kompella UB: Subconjunctivally administered celecoxib-PLGA microparticles sustain retinal drug levels and alleviate diabetes-induced oxidative stress in a rat model. Eur J Pharmacol 2005, 511:191-8. | Article | PubMed

26. Cheruvu NP, Amrite AC and Kompella UB: Effect of eye pigmentation on transscleral drug delivery. Invest Ophthalmol Vis Sci 2008, 49:33341. | Article | PubMed Abstract | PubMed Full Text

27. Niwa T, Takeuchi H, Hino T, Kunou N, Kawashima Y: Preparations of biodegradable nanospheres of water-soluble and insoluble drugs with D, L-lactide/glycolide copolymer by a novel spontaneous emulsification solvent diffusion method, and the drug release behavior. Journal of controlled release 1993, 25:89-98. | Article

28. El-Shabouri MH: Positively charged nanoparticles for improving the oral bioavailability of cyclosporin-A. Int J Pharm 2002, 249:101-8. | Article I PubMed

29. Ibrahim MM, Abd-Elgawad AE, Soliman OA and Jablonski MM: Nanoparticle-based topical ophthalmic formulations for sustained celecoxib release. J Pharm Sci 2013. | Article | PubMed

30. Liu Z, Li J, Nie S, Liu H, Ding P and Pan W: Study of an alginate/HPMCbased in situ gelling ophthalmic delivery system for gatifloxacin. Int J Pharm 2006, 315:12-7. | Article | PubMed

31. Kuzma JW, Bohnenblust SE: Basic Statistics for the Health Sciences. New York: NY: McGraw-Hill Education; 2005.

32. Zhang $Y$ and Zhuo RX: Synthesis, characterization, and in vitro 5-Fu release behavior of poly(2,2-dimethyltrimethylene carbonate)poly(ethylene glycol)-poly(2,2-dimethyltrimethylene carbonate) nanoparticles. J Biomed Mater Res A 2006, 76:674-80. | Article | PubMed

33. López-Montilla JC, Herrera-Morales PE, Pandey S, Shah DO Spontaneous emulsification: mechanisms, physicochemical aspects, modeling, and applications. Journal of dispersion science and technology 2002, 23:219-268. | Article

34. Mao S, Xu J, Cai C, Germershaus O, Schaper A and Kissel T: Effect of WOW process parameters on morphology and burst release of FITCdextran loaded PLGA microspheres. Int J Pharm 2007, 334:137-48. | Article I PubMed

35. Sahoo SK, Panyam J, Prabha S and Labhasetwar V: Residual polyvinyl alcohol associated with poly (D,L-lactide-co-glycolide) nanoparticles affects their physical properties and cellular uptake. J Control Release 2002, 82:105-14. | Article | PubMed

36. Redhead HM, Davis SS and Illum L: Drug delivery in poly(lactide-coglycolide) nanoparticles surface modified with poloxamer 407 and poloxamine 908: in vitro characterisation and in vivo evaluation. J Control Release 2001, 70:353-63. I Article I PubMed

37. Scholes PD, Coombes AG, Illum L, Davis SS, Watts JF, Ustariz C, Vert $M$ and Davies MC: Detection and determination of surface levels of poloxamer and PVA surfactant on biodegradable nanospheres using SSIMS and XPS. J Control Release 1999, 59:261-78. I Article I PubMed

38. Tan Q, Liu W, Guo C and Zhai G: Preparation and evaluation of quercetin-loaded lecithin-chitosan nanoparticles for topical delivery. Int J Nanomedicine 2011, 6:1621-30. | Article | PubMed Abstract | PubMed Full Text

39. Mainardes RM and Evangelista RC: PLGA nanoparticles containing praziquantel: effect of formulation variables on size distribution. Int $J$ Pharm 2005, 290:137-44. | Article | PubMed

40. Tripathi A, Gupta R, Saraf SA: PLGA nanoparticles of anti tubercular drug: Drug loading and release studies of a water in-soluble drug. Int J PharmTech Res 2010, 2:2116-2123. I Pdf

41. Yadav KS and Sawant KK: Modified nanoprecipitation method for preparation of cytarabine-loaded PLGA nanoparticles. AAPS PharmSciTech 2010, 11:1456-65. | Article | PubMed Abstract | PubMed Full Text

42. Sonaje K, Chen YJ, Chen HL, Wey SP, Juang JH, Nguyen HN, Hsu CW, Lin KJ and Sung HW: Enteric-coated capsules filled with freeze-dried chitosan/poly(gamma-glutamic acid) nanoparticles for oral insulin delivery. Biomaterials 2010, 31:3384-94. | Article | PubMed Abstract I PubMed Full Text
43. Hafner A, Durrigl M, Pepic I, Filipovic-Grcic J: Short- and longterm stability of lyophilised melatonin-loaded lecithin/chitosan nanoparticles. Chem Pharm Bull (Tokyo) 2011, 59:1117-1123. I Article

44. De Chasteigner S, Cavé G, Fessi H, Devissaguet JP, Puisieux F: Freezedrying of itraconazole-loaded nanosphere suspensions: a feasibility study. Drug development research 1996, 38:116-124. | Article

45. Seijo B, Fattal E, Roblot-Treupel L, Couvreur P: Design of nanoparticles of less than $\mathbf{5 0 ~} \mathbf{n m}$ diameter: preparation, characterization and drug loading. International Journal of Pharmaceutics 1990, 62:1-7. I Article

46. Scholes $\mathrm{P}$, Coombes A, Illum L, Daviz S, Vert M, et al.: The preparation of sub-200 nmpoly (lactide-co-glycolide) microspheres for sitespecific drug delivery. Journal of controlled release 1993, 25:145-153. I Article

47. Kim TH, Jeong YI, Jin SG, Pei J, Jung TY, Moon KS, Kim IY, Kang SS and Jung S: Preparation of polylactide-co-glycolide nanoparticles incorporating celecoxib and their antitumor activity against brain tumor cells. Int J Nanomedicine 2011, 6:2621-31. | Article | PubMed Abstract | PubMed Full Text

48. USP29-NF24. "The United States Pharmacopeia" 29th, The National formulary 24th: United States Pharmacopeial Convention Inc. MD; 2005.

49. Wu H, Liu Z, Peng J, Li L, Li N, Li J and Pan H: Design and evaluation of baicalin-containing in situ pH-triggered gelling system for sustained ophthalmic drug delivery. Int J Pharm 2011, 410:31-40. | Article | PubMed

50. Hammer ME and Burch TG: Viscous corneal protection by sodium hyaluronate, chondroitin sulfate, and methylcellulose. Invest Ophthalmol Vis Sci 1984, 25:1329-32. | Article | PubMed

51. Lin HR and Sung KC: Carbopol/pluronic phase change solutions for ophthalmic drug delivery. J Control Release 2000, 69:379-88. I Article | PubMed

52. Huang YY, Chung TW and Tzeng TW: A method using biodegradable polylactides/polyethylene glycol for drug release with reduced initial burst. Int J Pharm 1999, 182:93-100. I Article I PubMed

53. Garcia-Fuentes $M$, Torres D and Alonso MJ: New surface-modified lipid nanoparticles as delivery vehicles for salmon calcitonin. Int J Pharm 2005, 296:122-32. | Article | PubMed

54. Budhian A, Siegel SJ and Winey KI: Controlling the in vitro release profiles for a system of haloperidol-loaded PLGA nanoparticles. Int J Pharm 2008, 346:151-9. | Article | PubMed

55. Leroux JC, Allémann E, De Jaeghere F, Doelker E, Gurny R: Biodegradable nanoparticles-from sustained release formulations to improved site specific drug delivery. Journal of controlled release 1996, 39:339-350. | Article

56. Budai L, Hajdu M, Budai M, Grof P, Beni S, Noszal B, Klebovich I and Antal I: Gels and liposomes in optimized ocular drug delivery: studies on ciprofloxacin formulations. Int J Pharm 2007, 343:34-40. | Article I PubMed

57. Tamizharasi S, Rathi JC and Rathi V: Formulation, and Evaluation of Pentoxifylline-Loaded Poly(epsilon-caprolactone) Microspheres. Indian J Pharm Sci 2008, 70:333-7. | Article | PubMed Abstract | PubMed Full Text

58. Korsmeyer RW, Gurny R, Doelker E, Buri P, Peppas NA: Mechanisms of solute release from porous hydrophilic polymers. International Journal of Pharmaceutics 1983, 15:25-35. | Article

59. Dash S, Murthy PN, Nath L and Chowdhury P: Kinetic modeling on drug release from controlled drug delivery systems. Acta Pol Pharm 2010, 67:217-23. | Pdf | PubMed

60. German EJ, Hurst MA and Wood D: Reliability of drop size from multidose eye drop bottles: is it cause for concern? Eye (Lond) 1999, 13 ( Pt 1):93-100. | Article | PubMed

61. Nogueira NP, Reis PA, Laranja GA, Pinto AC, Aiub CA, Felzenszwalb I, Paes MC, Bastos FF, Bastos VL, Sabino KC and Coelho MG: In vitro and in vivo toxicological evaluation of extract and fractions from Baccharis trimera with anti-inflammatory activity. J Ethnopharmacol 2011, 138:513-22. | Article | PubMed

62. Liu Y, Wang T, He F, Liu Q, Zhang D, Xiang S, Su S and Zhang J: An 
Ibrahim et al. Journal of Pharmaceutical Technology \& Drug Research 2013,

http://www.hoajonline.com/journals/pdf/2050-120X-2-7.pdf

efficient calcium phosphate nanoparticle-based nonviral vector for gene delivery. Int I Nanomedicine 2011, 6:721-7. | Article | PubMed Abstract | PubMed Full Text

63. Caamal-Fuentes E, Torres-Tapia LW, Sima-Polanco P, Peraza-Sanchez SR and Moo-Puc R: Screening of plants used in Mayan traditional medicine to treat cancer-like symptoms. J Ethnopharmacol 2011, 135:719-24. | Article | PubMed

64. Staudacher I, Wang L, Wan X, Obers S, Wenzel W, Tristram F, Koschny R, Staudacher K, Kisselbach J, Koelsch P, Schweizer PA, Katus HA, Ficker E and Thomas D: hERG K+ channel-associated cardiac effects of the antidepressant drug desipramine. Naunyn Schmiedebergs Arch Pharmacol 2011, 383:119-39. | Article | PubMed

65. Vandervoort J and Ludwig A: Biocompatible stabilizers in the preparation of PLGA nanoparticles: a factorial design study. Int J Pharm 2002, 238:77-92. | Article | PubMed

\section{Citation:}

Ibrahim M M, Abd-Elgawad A-E H, Soliman O A-E and Jablonski M M: Natural bioadhesive biodegradable nanoparticles-based topical ophthalmic formulations for sustained celecoxib release: in vitro study. journal of Pharmaceutical Technology and Drug Research 2013, 2:7.

http://dx.doi.org/10.7243/2050-120X-2-7 